\title{
On Generalized c*-continuous Functions and Generalized c*-irresolute Functions in Topological Spaces
}

\author{
S. Malathi ${ }^{1 * *}$, S. Nithyanantha Jothi ${ }^{2}$ \\ ${ }^{1}$ Aditanar College of Arts and Science, Tiruchendur-628215, Tamilnadu, India \\ ${ }^{2}$ Department of Mathematics, Aditanar College of Arts and Science, Tiruchendur-628215, Tamilnadu, India \\ *Corresponding author: malathis2795@gmail.com
}

Received September 22, 2018; Revised October 29, 2018; Accepted December 13, 2018

\begin{abstract}
The aim of this paper is to introduce the notion of generalized $c^{*}$-continuous functions and generalized $\mathrm{c}^{*}$-irresolute functions in topological spaces and study their basic properties.
\end{abstract}

Keywords: $g c$-continuous functions and $g c^{*}$-irresolute functions

Cite This Article: S. Malathi, and S. Nithyanantha Jothi, "On Generalized c*-continuous Functions and Generalized c*-irresolute Functions in Topological Spaces." Turkish Journal of Analysis and Number Theory, vol. 6, no. 6 (2018): 164-168. doi: 10.12691/tjant-6-6-4.

\section{Introduction}

In 1963, Norman Levine introduced semi-open sets in topological spaces. Also in 1970, he introduced the concept of generalized closed sets. Palaniappan and Rao introduced regular generalized closed (briefly, rg-closed) sets in 1993. In the year 1996, Andrijevic introduced and studied b-open sets. Gnanambal introduced generalized preregular closed (briefly gpr-closed) sets in 1997. N. Levine introduced the concept of semi-continuous function in 1963. In 1980, Jain introduced totally continuous functions. In 1995, T. M. Nour introduced the concept of totally semi-continuous functions as a generalization of totally continuous functions. In 2011, S.S. Benchalli and Umadevi I Neeli introduced the concept of semi-totally continuous functions in topological spaces. In this paper we introduce generalized $\mathrm{c}^{*}$-continuous functions and generalized $\mathrm{C}^{*}$-irresolute functions in topological spaces and study their basic properties.

Section 2 deals with the preliminary concepts. In section 3 , generalized $c^{*}$-continuous functions are introduced and study their basic properties. The generalized $\mathrm{c}^{*}$-irresolute functions in topological spaces are introduced in section 4 .

\section{Preliminaries}

Throughout this paper $\mathrm{X}$ denotes a topological space on which no separation axiom is assumed. For any subset $\mathrm{A}$ of $\mathrm{X}, \operatorname{cl}(\mathrm{A})$ denotes the closure of $\mathrm{A}$, int(A) denotes the interior of $\mathrm{A}, \operatorname{pcl}(\mathrm{A})$ denotes the pre-closure of $\mathrm{A}$ and bcl(A) denotes the b-closure of $\mathrm{A}$. Further $\mathrm{X} \backslash \mathrm{A}$ denotes the complement of $\mathrm{A}$ in $\mathrm{X}$. The following definitions are very useful in the subsequent sections.

Definition: 2.1 A subset A of a topological space $\mathrm{X}$ is called

i. a semi-open set [1] if $\mathrm{A} \subseteq \mathrm{cl}(\operatorname{int}(\mathrm{A}))$ and a semi-closed set if $\operatorname{int}(\mathrm{cl}(\mathrm{A})) \subseteq \mathrm{A}$.

ii. a pre-open set [2] if $A \subseteq \operatorname{int}(\mathrm{cl}(\mathrm{A}))$ and a pre-closed set if $\operatorname{cl}(\operatorname{int}(\mathrm{A})) \subseteq \mathrm{A}$.

iii. a regular-open set [3] if $A=\operatorname{int}(\mathrm{cl}(\mathrm{A}))$ and a regularclosed set if $A=c l(\operatorname{int}(A))$.

iv. a $\gamma$-open set [4] (b-open set [5]) if $\mathrm{A} \subseteq \mathrm{cl}(\operatorname{int}(\mathrm{A})$ ) vint(cl(A)) and a $\gamma$-closed set (b-closed set) if $\operatorname{int}(\mathrm{cl}(\mathrm{A})) \cap \mathrm{cl}(\mathrm{int}(\mathrm{A})) \subseteq \mathrm{A}$.

Definition: 2.2 A subset A of a topological space $\mathrm{X}$ is said to be

i. a clopen set if $\mathrm{A}$ is both open and closed in X.

ii. a semi-clopen set if $\mathrm{A}$ is both semi-open and semi-closed in X.

Definition: 2.3 [6] A subset A of a topological space $X$ is

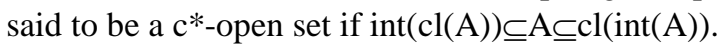

Definition: 2.4 A subset A of a topological space $X$ is called

i. a generalized closed set (briefly, g-closed) [7] if $\operatorname{cl}(\mathrm{A}) \subseteq \mathrm{H}$ whenever $\mathrm{A} \subseteq \mathrm{H}$ and $\mathrm{H}$ is open in $\mathrm{X}$.

ii. a regular-generalized closed set (briefly, rg-closed) [8] if $\mathrm{cl}(\mathrm{A}) \subseteq \mathrm{H}$ whenever $\mathrm{A} \subseteq \mathrm{H}$ and $\mathrm{H}$ is regular-open in $\mathrm{X}$.

iii. a generalized pre-regular closed set (briefly, gpr-closed) [9] if $\operatorname{pcl}(\mathrm{A}) \subseteq \mathrm{H}$ whenever $\mathrm{A} \subseteq \mathrm{H}$ and $\mathrm{H}$ is regular-open in $\mathrm{X}$.

iv. a regular generalized b-closed set (briefly,

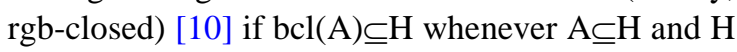
is regular-open in $\mathrm{X}$.

v. a regular weakly generalized closed set (briefly, rwg-closed) [11] if $\operatorname{cl}(\operatorname{int}(\mathrm{A})) \subseteq \mathrm{H}$ whenever $\mathrm{A} \subseteq \mathrm{H}$ and $\mathrm{H}$ is regular-open in $\mathrm{X}$. 
vi. a semi-generalized b-closed set (briefly, sgb-closed) [12] if $\operatorname{bcl}(\mathrm{A}) \subseteq \mathrm{H}$ whenever $\mathrm{A} \subseteq \mathrm{H}$ and $\mathrm{H}$ is semi-open in $\mathrm{X}$.

vii. a weakly closed set (briefly, w-closed) [13] (equivalently, $\hat{g}$-closed [14]) if $\mathrm{cl}(\mathrm{A}) \subseteq \mathrm{H}$ whenever $\mathrm{A} \subseteq \mathrm{H}$ and $\mathrm{H}$ is semi-open in $\mathrm{X}$.

The complements of the above mentioned closed sets are their respectively open sets.

Definition: 2.5 [6] A subset A of a topological space $X$ is said to be a generalized $\mathrm{c}^{*}$-closed set (briefly, gc*-closed set) if $\mathrm{cl}(\mathrm{A}) \subseteq \mathrm{H}$ whenever $\mathrm{A} \subseteq \mathrm{H}$ and $\mathrm{H}$ is $\mathrm{c}^{*}$-open. The complement of the gc*-closed set is gc*-open [15].

Definition: 2.6 A function $\mathrm{f}: \mathrm{X} \rightarrow \mathrm{Y}$ is called

i. semi-continuous [1] if the inverse image of each open subset of $\mathrm{Y}$ is semi-open in $\mathrm{X}$.

ii. totally-continuous [16] if the inverse image of every open subset of $\mathrm{Y}$ is clopen in $\mathrm{X}$.

iii. strongly-continuous [3] if the inverse image of every subset of $\mathrm{Y}$ is clopen subset of $\mathrm{X}$.

iv. totally semi-continuous [17] if the inverse image of every open subset of $\mathrm{Y}$ is semi- clopen in $\mathrm{X}$.

v. strongly semi-continuous [17] if the inverse image of every subset of $\mathrm{Y}$ is semi- clopen in $\mathrm{X}$.

vi. semi-totally continuous [18] if the inverse image of every semi- open subset of $\mathrm{Y}$ is clopen in $\mathrm{X}$.

vii. semi-totally semi-continuous [19] if the inverse image of every semi-open subset of $\mathrm{Y}$ is semiclopen in $\mathrm{X}$.

viii. rg-continuous [9] if inverse image of every closed subset of $\mathrm{Y}$ is rg-closed in $\mathrm{X}$.

viii. gpr-continuous [9] if inverse image of every closed subset of $\mathrm{Y}$ is gpr-closed in $\mathrm{X}$.

ix. W-continuous [20] ( $\hat{g}$-continuous [14]) if inverse image of every closed subset of $\mathrm{Y}$ is $\mathrm{w}$-closed in $\mathrm{X}$.

Definition: 2.7 [21] A function $\mathrm{f}: \mathrm{X} \rightarrow \mathrm{Y}$ is called an irresolute function if the inverse image of every semi-open subset of $\mathrm{Y}$ is semi-open in $\mathrm{X}$.

\section{Generalized c*-continuous Functions}

In this section, we introduce generalized $c^{*}$-continuous functions and study its basic properties. Now, we begin with the definition of generalized $\mathrm{c}^{*}$-continuous function.

Definition: 3.1 Let $X$ and $Y$ be two topological spaces. A function $\mathrm{f}: \mathrm{X} \rightarrow \mathrm{Y}$ is called a generalized $\mathrm{c}^{*}$-continuous (briefly, gc*-continuous) function if $\mathrm{f}^{-1}(\mathrm{~V})$ is gc*-closed in X for every closed set $\mathrm{V}$ of $\mathrm{Y}$.

Example: 3.2 Let $X=\{a, b, c, d\}$ with topology $\tau=\{\phi,\{a\}$, $\{b\},\{a, b\},\{b, c\},\{a, b, c\},\{a, b, d\}, X\}$ and $Y=\{1,2,3\}$ with topology $\sigma=\{\phi,\{1\}, \mathrm{Y}\}$. Define $\mathrm{f}: \mathrm{X} \rightarrow \mathrm{Y}$ by $\mathrm{f}(\mathrm{a})=\mathrm{f}(\mathrm{d})=2$, $f(b)=3, f(c)=1$. Then the inverse image of every closed set in $\mathrm{Y}$ is $\mathrm{gc}^{*}$-closed in $\mathrm{X}$. Hence $\mathrm{f}: \mathrm{X} \rightarrow \mathrm{Y}$ is gc*-continuous.

Proposition: 3.3 Let $\mathrm{X}, \mathrm{Y}$ be two topological spaces. Then $\mathrm{f}: \mathrm{X} \rightarrow \mathrm{Y}$ is $\mathrm{gc}^{*}$-continuous if and only if $\mathrm{f}^{-1}(\mathrm{U})$ is gc*-open in $\mathrm{X}$ for every open set $\mathrm{U}$ of $\mathrm{Y}$.

Proof: Suppose $\mathrm{f}: \mathrm{X} \rightarrow \mathrm{Y}$ is gc*-continuous. Let $\mathrm{U}$ be an open set in $Y$. Then $Y \backslash U$ is a closed set in $Y$. This implies, $\mathrm{f}^{-1}(\mathrm{Y} \backslash \mathrm{U})$ is a $\mathrm{gc}^{*}$-closed set in $X$. Since $\mathrm{f}^{-1}(\mathrm{Y} \backslash U)=X \backslash \mathrm{f}^{-}$ ${ }^{1}(U)$, we have $X \backslash f^{-1}(U)$ is a gc*-closed set in $X$. This implies, $\mathrm{f}^{-1}(\mathrm{U})$ is a $\mathrm{gc}^{*}$-open set in $\mathrm{X}$. Conversely, assume that $\mathrm{f}^{-1}(\mathrm{U})$ is $\mathrm{gc}^{*}$-open in $\mathrm{X}$ for every open set $\mathrm{U}$ in $\mathrm{Y}$. Let
$\mathrm{V}$ be a closed set in $\mathrm{Y}$. Then $\mathrm{Y} \backslash \mathrm{V}$ is open in $\mathrm{Y}$. Therefore, $f^{-1}(Y \backslash V)$ is gc*-open in $X$. That is, $X \backslash f^{-1}(V)$ is gc*-open in $X$. This implies, $f^{-1}(V)$ is $g^{*}$-closed in $X$. Therefore, $\mathrm{f}$ is $\mathrm{gc}^{*}$-continuous.

Proposition: 3.4 Let $\mathrm{X}, \mathrm{Y}$ be two topological spaces. Then every continuous function is gc*-continuous.

Proof: Let $\mathrm{f}: \mathrm{X} \rightarrow \mathrm{Y}$ be a continuous function. Let $\mathrm{V}$ be a closed set in $Y$. Then $\mathrm{f}^{-1}(\mathrm{~V})$ is a closed set in $\mathrm{X}$. By Proposition 4.3 [6], $\mathrm{f}^{-1}(\mathrm{~V})$ is $\mathrm{gc}^{*}$-closed in $\mathrm{X}$. Therefore, $\mathrm{f}$ is gc*-continuous.

The converse of the Proposition 3.4 need not be true as seen from the following example.

Example: 3.5 Let $X=\{1,2,3,4\}$ and $Y=\{a, b, c, d, e\}$. Then, clearly $\tau=\{\phi,\{1\},\{2\},\{3\},\{1,2\},\{1,3\},\{2,3\},\{3,4\}$, $\{1,2,3\},\{2,3,4\},\{1,3,4\}, X\}$ is a topology on $X$ and $\sigma=\{\phi,\{\mathrm{a}\},\{\mathrm{d}\},\{\mathrm{e}\},\{\mathrm{a}, \mathrm{d}\},\{\mathrm{a}, \mathrm{e}\},\{\mathrm{d}, \mathrm{e}\},\{\mathrm{a}, \mathrm{d}, \mathrm{e}\}, \mathrm{Y}\}$ is a topology on $\mathrm{Y}$. Define $\mathrm{f}: \mathrm{X} \rightarrow \mathrm{Y}$ by $\mathrm{f}(1)=\mathrm{b}, \mathrm{f}(2)=\mathrm{f}(3)=\mathrm{d}$, $\mathrm{f}(4)=e$. Then $\mathrm{f}$ is $\mathrm{gc}^{*}$-continuous. Consider the closed set $\{a, b, c, d\}$ in $Y$. Then $f^{-1}(\{a, b, c, d\})=\{1,2,3\}$, which is not a closed set in $\mathrm{X}$. Therefore, $\mathrm{f}$ is not continuous.

Proposition: 3.6 Let $\mathrm{X}, \mathrm{Y}$ be two topological spaces. Then every strongly-continuous function is gc*-continuous.

Proof: Let $\mathrm{f}: \mathrm{X} \rightarrow \mathrm{Y}$ be a strongly-continuous function and let $\mathrm{V}$ be a closed set in $\mathrm{Y}$. Then $\mathrm{f}^{-1}(\mathrm{~V})$ is a clopen set in $\mathrm{X}$. This implies, $\mathrm{f}^{-1}(\mathrm{~V})$ is closed in $\mathrm{X}$. By Proposition 4.3 [6], $\mathrm{f}^{-1}(\mathrm{~V})$ is $\mathrm{gc}^{*}$-closed. Therefore, $\mathrm{f}: \mathrm{X} \rightarrow \mathrm{Y}$ is gc*-continuous.

The converse of the Proposition 3.6 need not be true as seen from the following example.

Example: 3.7 Let $X=\{1,2,3,4,5\}$ and $Y=\{a, b, c, d\}$. Then, clearly $\tau=\{\varphi\{1\},\{4\},\{5\},\{1,4\},\{1,5\},\{4,5\},\{1,4,5\}, X\}$ is a topology on $X$ and $\sigma=\{\phi,\{a\},\{c\},\{d\},\{a, c\},\{a, d\}$, $\{c, d\},\{a, c, d\}, Y\}$ is a topology on $Y$. Define $\mathrm{f}: \mathrm{X} \rightarrow \mathrm{Y}$ by $f(1)=f(4)=f(5)=b, f(2)=f(3)=a$. Then $f$ is $g c *$-continuous. Consider the subset $\{a\}$ in Y. Then $f^{-1}(\{a\})=\{2,3\}$, which is not a clopen set in $\mathrm{X}$. Therefore, $\mathrm{f}$ is not strongly-continuous. Proposition: 3.8 Let X,Y be two topological spaces. Then every semi-totally continuous function is gc*-continuous.

Proof: Let $\mathrm{f}: \mathrm{X} \rightarrow \mathrm{Y}$ be a semi-totally continuous function and let $\mathrm{V}$ be an open set in $\mathrm{Y}$. Since every open set is semi-open, we have $\mathrm{V}$ is semi-open in $\mathrm{Y}$. Therefore, by our assumption, $\mathrm{f}^{-1}(\mathrm{~V})$ is clopen in $\mathrm{X}$. Then by Proposition 3.7 [15], $\mathrm{f}^{-1}(\mathrm{~V})$ is a gc*-open set in $\mathrm{X}$. Therefore, $\mathrm{f}: \mathrm{X} \rightarrow \mathrm{Y}$ is gc*-continuous.

The converse of the Proposition 3.8 need not be true as seen from the following example.

Example: 3.9 In Example 3.5, define $\mathrm{f}: \mathrm{X} \rightarrow \mathrm{Y}$ by $\mathrm{f}(1)=\mathrm{b}$, $\mathrm{f}(2)=\mathrm{f}(3)=\mathrm{d}, \mathrm{f}(4)=e$. Then $\mathrm{f}$ is $\mathrm{gc}^{*}$-continuous. Consider the semi-open set $\{d\}$ in $Y$. Then $f^{-1}(\{d\})=\{2,3\}$, which is not a clopen set in $\mathrm{X}$. Therefore, $\mathrm{f}$ is not semi-totally continuous.

Proposition: 3.10 Let $\mathrm{X}, \mathrm{Y}$ be two topological spaces. Then every totally-continuous function is gc*-continuous.

Proof: Let $\mathrm{f}: \mathrm{X} \rightarrow \mathrm{Y}$ be a totally-continuous function and let $\mathrm{V}$ be an open set in $\mathrm{Y}$. Then $\mathrm{f}^{-1}(\mathrm{~V})$ is clopen in $\mathrm{X}$. Therefore, by Proposition $3.7[15], \mathrm{f}^{-1}(\mathrm{~V})$ is $\mathrm{gc}^{*}$-open in $\mathrm{X}$. Therefore, $\mathrm{f}$ is $\mathrm{gc}^{*}$-continuous.

The converse of the Proposition 3.10 need not be true as seen from the following example.

Example: 3.11 In Example 3.5, define $\mathrm{f}: \mathrm{X} \rightarrow \mathrm{Y}$ by $\mathrm{f}(1)=\mathrm{b}, \mathrm{f}(2)=\mathrm{f}(3)=\mathrm{d}, \mathrm{f}(4)=e$. Then $\mathrm{f}$ is $\mathrm{gc}^{*}$-continuous. Consider the open set $\{d\}$ in $Y$. Then $f^{-1}(\{d\})=\{2,3\}$, which is not a clopen set in $\mathrm{X}$. Therefore, $\mathrm{f}$ is not a totally-continuous function. 
Proposition: 3.12 Let $\mathrm{X}, \mathrm{Y}$ be two topological space. Then every $\mathrm{w}$-continuous ( $\hat{\mathrm{g}}$-continuous) function is gc*-continuous.

Proof: Let $\mathrm{f}: \mathrm{X} \rightarrow$ Y be a w-continuous function. Let $\mathrm{V}$ be a closed set in $Y$. Then $f^{-1}(V)$ is $w$-closed in $X$. By Proposition 4.5 [6], we have $\mathrm{f}^{-1}(\mathrm{~V})$ is $\mathrm{gc}^{*}$-closed in $\mathrm{X}$. Therefore, $\mathrm{f}$ is gc*-cotinuous.

The converse of the Proposition 3.12 need not be true as seen from the following example.

Example: 3.13 Let $X=\{1,2,3\}$ and $Y=\{a, b, c\}$. Then, clearly $\tau=\{\varphi\{2\},\{1,2\}, X\}$ is a topology on $\mathrm{X}$ and $\sigma=\{\varphi\{a\}, Y\}$ is a topology on $Y$. Define $f: X \rightarrow Y$ by $f(1)=a, f(2)=c, f(3)=b$. Then $f$ is $g c *$ - continuous. Consider the closed set $\{b, c\}$ in $Y$. Then $f^{-1}(\{b, c\})=\{2,3\}$ which is not a w-closed set in $\mathrm{X}$. Therefore, $\mathrm{f}$ is not a w-continuous function.

Proposition: 3.14 Let $\mathrm{X}, \mathrm{Y}$ be two topological spaces. Then every gc*-continuous function is rg-continuous.

Proof: Letf: $\mathrm{X} \rightarrow \mathrm{Y}$ be a gc*-continuous function. Let $\mathrm{V}$ be a closed set in $Y$. Then $\mathrm{f}^{-1}(\mathrm{~V})$ is a gc*-closed set in $\mathrm{X}$. By Proposition 4.7 [6], we have $\mathrm{f}^{-1}(\mathrm{~V})$ is rg-closed (gprclosed) in $\mathrm{X}$. Therefore, $\mathrm{f}$ is rg-continuous.

Proposition: 3.15 Let $\mathrm{X}, \mathrm{Y}$ be two topological spaces. Then every gc*-continuous function is gpr-continuous.

Proof: Let $\mathrm{f}: \mathrm{X} \rightarrow \mathrm{Y}$ be a gc*-continuous function. Let $\mathrm{V}$ be a closed set in $Y$. Then $\mathrm{f}^{-1}(\mathrm{~V})$ is a gc*-closed set in $\mathrm{X}$. By Proposition 4.9 [6], we have $\mathrm{f}^{-1}(\mathrm{~V})$ is gpr-closed in $\mathrm{X}$. Therefore, $\mathrm{f}$ is gpr-continuous.

The converse of Proposition 3.14 and Proposition 3.15 need not be true as seen from the following example.

Example: 3.16 Let $\mathrm{X}=\{\mathrm{a}, \mathrm{b}, \mathrm{c}, \mathrm{d}$, e $\}$ and $\mathrm{Y}=\{1,2,3,4\}$. Then, clearly $\tau=\{\varphi\{\mathrm{a}\},\{\mathrm{d}\},\{\mathrm{e}\},\{\mathrm{a}, \mathrm{d}\},\{\mathrm{a}, \mathrm{e}\},\{\mathrm{d}, \mathrm{e}\},\{\mathrm{a}, \mathrm{d}, \mathrm{e}\}, \mathrm{X}\}$ is a topology on $X$ and $\sigma=\{\varphi\{1\},\{3\},\{4\},\{1,3\},\{1,4\}$, $\{3,4\},\{1,3,4\}, Y\}$ is a topology on $\mathrm{Y}$. Define $\mathrm{f}: \mathrm{X} \rightarrow \mathrm{Y}$ by $f(a)=1, \quad f(b)=3, \quad f(c)=2, \quad f(d)=f(e)=4$. Then $f$ is rg-continuous and gpr-continuous. Consider the closed set $\{2,4\}$ in $\mathrm{Y}$. Then $\mathrm{f}^{-1}(\{2,4\})=\{\mathrm{c}, \mathrm{d}, \mathrm{e}\}$, which is not a gc*-closed set in $\mathrm{X}$. Therefore $\mathrm{f}$ is not gc*-continuous.

The semi-continuous functions and gc*-continuous functions are independent. For example, In Example 3.7, define $\mathrm{f}: \mathrm{X} \rightarrow \mathrm{Y}$ by $\mathrm{f}(1)=\mathrm{f}(2)=\mathrm{a}, \mathrm{f}(3)=\mathrm{b}, \mathrm{f}(4)=\mathrm{f}(5)=\mathrm{d}$. Then $\mathrm{f}$ is semi-continuous. Consider the closed set $\{\mathrm{b}, \mathrm{c}, \mathrm{d}\}$ in $Y$. Then $\mathrm{f}^{-1}(\{\mathrm{~b}, \mathrm{c}, \mathrm{d}\})=\{3,4,5\}$, which is not a gc*-closed set in $\mathrm{X}$. Therefore, $\mathrm{f}$ is not a gc*-continuous. Now, define $\mathrm{g}: \mathrm{X} \rightarrow \mathrm{Y}$ by $\mathrm{g}(1)=\mathrm{g}(4)=\mathrm{g}(5)=\mathrm{b}, \mathrm{g}(2)=\mathrm{g}(3)=\mathrm{a}$. Then $\mathrm{g}$ is

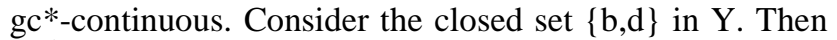
$\mathrm{g}^{-1}(\{\mathrm{~b}, \mathrm{~d}\})=\{1,4,5\}$, which is not a semi-closed set in $\mathrm{X}$. Therefore, $g$ is not a semi-continuous function.

The totally-semi continuous functions and gc*-continuous functions are independent. For example, let $X=\{1,2,3,4\}$ and $\mathrm{Y}=\{\mathrm{a}, \mathrm{b}, \mathrm{c}, \mathrm{d}, \mathrm{e}\}$. Then, clearly $\tau=\{\varphi\{1\},\{2\},\{1,2\}$, $\{1,3\},\{1,2,3\}, X\}$ is a topology on $X$ and $\sigma=\{\varphi\{a\},\{d\}$, $\{\mathrm{e}\},\{\mathrm{a}, \mathrm{d}\},\{\mathrm{a}, \mathrm{e}\},\{\mathrm{d}, \mathrm{e}\},\{\mathrm{a}, \mathrm{d}, \mathrm{e}\}, \mathrm{Y}\}$ is a topology on $\mathrm{Y}$. Define $\mathrm{f}: \mathrm{X} \rightarrow \mathrm{Y}$ by $\mathrm{f}(1)=\mathrm{a}, \mathrm{f}(2)=\mathrm{b}, \mathrm{f}(3)=\mathrm{f}(4)=\mathrm{c}$. Then $\mathrm{f}$ is gc*-continuous. Consider the open set $\{a\}$ in $Y$. Then $\mathrm{f}$ ${ }^{1}(\{a\})=\{1\}$, which is not a semi-clopen set in $X$. Therefore, $\mathrm{f}$ is not a totally-semi continuous function. Now, define $\mathrm{g}: \mathrm{X} \rightarrow \mathrm{Y}$ by $\mathrm{g}(1)=\mathrm{g}(3)=\mathrm{a}, \mathrm{g}(2)=\mathrm{g}(4)=\mathrm{d}$. Then $\mathrm{g}$ is totally-semi continuous. Consider the closed set $\{a, b, c\}$ in Y. Then $g^{-1}(\{a, b, c\})=\{1,3\}$, which is not a gc*-closed set in $\mathrm{X}$. Therefore, $\mathrm{g}$ is not a gc*-continuous function.

The strongly semi-continuous functions and gc*-continuous functions are independent. For example, let $X=\{1,2,3,4,5\}$ and $\mathrm{Y}=\{\mathrm{a}, \mathrm{b}, \mathrm{c}, \mathrm{d}, \mathrm{e}\}$. Then, clearly $\tau=\{\varphi\{1\},\{4\},\{5\}$, $\{1,4\},\{1,5\},\{4,5\},\{1,4,5\}, X\}$ is a topology on $X$ and $\sigma=\{\varphi\{\mathrm{a}, \mathrm{b}\},\{\mathrm{c}, \mathrm{d}\},\{\mathrm{a}, \mathrm{b}, \mathrm{c}, \mathrm{d}\}, \mathrm{Y}\}$ is a topology on $\mathrm{Y}$. Define $\mathrm{f}: \mathrm{X} \rightarrow \mathrm{Y}$ by $\mathrm{f}(1)=\mathrm{f}(2)=\mathrm{a}, \mathrm{f}(3)=\mathrm{f}(5)=\mathrm{c}, \mathrm{f}(4)=\mathrm{d}$. Then $\mathrm{f}$ is strongly-semi continuous. Consider the closed set $\{a, b, e\}$ in $Y$. Then $\mathrm{f}^{-1}(\{a, b, e\})=\{1,2\}$, which is not a $\mathrm{gc}^{*}$-closed set in $\mathrm{X}$. Therefore, $\mathrm{f}$ is not $\mathrm{gc}^{*}$-continuous. Now, define $\mathrm{g}: \mathrm{X} \rightarrow \mathrm{Y}$ by $\mathrm{g}(1)=\mathrm{g}(3)=\mathrm{g}(4)=\mathrm{g}(5)=\mathrm{e}, \mathrm{g}(2)=\mathrm{c}$. Then $\mathrm{g}$ is $\mathrm{gc}^{*}$-continuous. Consider the subset $\{\mathrm{c}\}$ in $\mathrm{Y}$. Then $g^{-1}(\{c\})=\{2\}$, which is not a semi-clopen set in $X$. Therefore, $\mathrm{g}$ is not a strongly-semi continuous function.

The semi-totally semi-continuous functions and gc*-continuous functions are independent. For example, let $\mathrm{X}=\{1,2,3,4\}$ and $\mathrm{Y}=\{\mathrm{a}, \mathrm{b}, \mathrm{c}, \mathrm{d}, \mathrm{e}\}$. Then, clearly $\tau=\{\varphi\{1\},\{2\},\{1,2\},\{1,3\},\{1,2,3\}, X\}$ is a topology on $\mathrm{X}$ and $\sigma=\{\varphi\{\mathrm{a}\},\{\mathrm{d}\},\{\mathrm{e}\},\{\mathrm{a}, \mathrm{d}\},\{\mathrm{a}, \mathrm{e}\},\{\mathrm{d}, \mathrm{e}\},\{\mathrm{a}, \mathrm{d}, \mathrm{e}\}, \mathrm{Y}\}$ is $\mathrm{a}$ topology on $\mathrm{Y}$. Define $\mathrm{f}: \mathrm{X} \rightarrow \mathrm{Y}$ by $\mathrm{f}(1)=\mathrm{a}, \mathrm{f}(2)=\mathrm{b}$, $f(3)=f(4)=c$. Then $f$ is $g c *$-continuous. Consider the semi-open set $\{a, b\}$ in $Y$. Then $f^{-1}(\{a, b\})=\{1,2\}$, which is not a semi-clopen set in $X$. Therefore, $f$ is not a semi-totally semi-continuous function. Now, define $\mathrm{g}: \mathrm{X} \rightarrow \mathrm{Y}$ by $\mathrm{g}(1)=\mathrm{g}(3)=\mathrm{a}, \mathrm{g}(2)=\mathrm{g}(4)=\mathrm{d}$. Then $\mathrm{g}$ is semi-totally-semi-continuous. Consider the closed set $\{a, b, c\}$ in $Y$. Then $\mathrm{g}^{-1}(\{\mathrm{a}, \mathrm{b}, \mathrm{c}\})=\{1,3\}$, which is not $\mathrm{a}$ $\mathrm{gc}^{*}$-closed set in $\mathrm{X}$. Therefore, $\mathrm{g}$ is not a gc*-continuous function.

Proposition: 3.17 Let $\mathrm{X}, \mathrm{Y}$ be two topological spaces. Then for any bijective function $\mathrm{f}: \mathrm{X} \rightarrow \mathrm{Y}$, the following statements are equivalent.

i. $\mathrm{f}: \mathrm{X} \rightarrow \mathrm{Y}$ is $\mathrm{gc}^{*}$-continuous.

ii. $\mathrm{f}^{-1}: \mathrm{Y} \rightarrow \mathrm{X}$ is gc*-open.

Proof: (i) $\Rightarrow$ (ii) Assume that $\mathrm{f}: \mathrm{X} \rightarrow \mathrm{Y}$ is gc*-continuous. Let $\mathrm{U}$ be an open set in $\mathrm{Y}$. Since $\mathrm{f}$ is $\mathrm{gc}^{*}$-continuous, we have $\mathrm{f}^{-1}(\mathrm{U})$ is $\mathrm{gc}^{*}$-open in $\mathrm{X}$. Therefore, $\mathrm{f}^{-1}$ is a gc*-open map. (ii) $\Rightarrow$ (i) Assume that $\mathrm{f}^{-1}: \mathrm{Y} \rightarrow \mathrm{X}$ is a gc*-open map. Let $\mathrm{V}$ be an open subset of $\mathrm{Y}$. By our assumption, $\mathrm{f}^{-1}(\mathrm{~V})$ is $\mathrm{gc}^{*}$-open in $\mathrm{X}$. Therefore, $\mathrm{f}$ is $\mathrm{gc}^{*}$-continuous.

The composition of two gc*-continuous functions need not be gc*-continuous. For example, let $X=\{a, b, c\}$, $\mathrm{Y}=\{1,2,3\}, \mathrm{Z}=\{\mathrm{p}, \mathrm{q}, \mathrm{r}\}$. Then, clearly $\tau=\{\varphi\{\mathrm{b}\},\{\mathrm{c}\},\{\mathrm{b}, \mathrm{c}\}$, $\mathrm{X}\}$ is a topology on $\mathrm{X}, \sigma=\{\varphi\{1\}, Y\}$ is a topology on $\mathrm{Y}$ and $\eta=\{\varphi\{p\},\{p, q\}, Z\}$ is a topology on $Z$. Define $\mathrm{f}: \mathrm{X} \rightarrow \mathrm{Y}$ by $\mathrm{f}(\mathrm{a})=1, \mathrm{f}(\mathrm{b})=3, \mathrm{f}(\mathrm{c})=2$ and $\mathrm{g}: \mathrm{Y} \rightarrow \mathrm{Z}$ by $g(1)=q, g(2)=p, g(3)=r$. Then $f$ and $g$ are $g c^{*}$-continuous. Consider the closed set $\{r\}$ in $Z$. Then $(g \circ f)^{-1}(\{r\})=$ $\mathrm{f}^{-1}\left(\mathrm{~g}^{-1}(\{\mathrm{r}\})\right)=\mathrm{f}^{-1}(\{3\})=\{\mathrm{b}\}$, which is not a gc*-closed set in $X$. Therefore, gof is not a gc*-continuous function.

Proposition: 3.18 Let $\mathrm{X}, \mathrm{Y}$ and $\mathrm{Z}$ be topological spaces. If $\mathrm{f}: \mathrm{X} \rightarrow \mathrm{Y}$ is $\mathrm{gc}^{*}$-continuous and $\mathrm{g}: \mathrm{Y} \rightarrow \mathrm{Z}$ is continuous, then gof $: X \rightarrow Z$ is $\mathrm{gc}^{*}$-continuous.

Proof: Let $\mathrm{V}$ be a closed set in $\mathrm{Z}$. Since $\mathrm{g}$ is continuous, we have $g^{-1}(V)$ is closed in $Y$. Also, since $f$ is $\mathrm{gc}^{*}$-continuous, we have $\mathrm{f}^{-1}\left(\mathrm{~g}^{-1}(\mathrm{~V})\right)$ is gc*-closed in $\mathrm{X}$. But $f^{-1}\left(g^{-1}(V)\right)=(g \circ f)^{-1}(V)$. Therefore, $(g \circ f)^{-1}(V)$ is $\mathrm{gc}^{*}$-closed in $\mathrm{X}$. Hence gof is gc*-continuous.

Proposition: 3.19 Let $X, Y$ and $Z$ be topological spaces. If $\mathrm{f}: \mathrm{X} \rightarrow \mathrm{Y}$ and $\mathrm{g}: \mathrm{Y} \rightarrow \mathrm{Z}$ are continuous. Then gof $: \mathrm{X} \rightarrow$ $\mathrm{Z}$ is gc*-continuous.

Proof: Let V be a closed set in Z. Since $\mathrm{g}$ is continuous, we have $g^{-1}(V)$ is closed in $Y$. Also, since $f$ is continuous, we have $f^{-1}\left(g^{-1}(V)\right)$ is closed in $Y$. That is, $(g \circ f)^{-1}(V)$ is closed in Y. By Proposition 4.3 [6], $(\mathrm{g} \circ)^{-1}(\mathrm{~V})$ is $\mathrm{gc}^{*}$-closed in $\mathrm{Y}$. Therefore, gof is a $\mathrm{gc}^{*}$-continuous map. 


\section{Generalized c*-irresolute Functions}

In this section, we introduce generalized $c^{*}$-irresolute functions in topological spaces. Also, we discuss about some of their basic properties.

Definition: 4.1 Let $\mathrm{X}$ and $\mathrm{Y}$ be two topological spaces. A function $\mathrm{f}: \mathrm{X} \rightarrow \mathrm{Y}$ is said to be a generalized c*-irresolute (briefly, gc*-irresolute) function if $\mathrm{f}^{-1}(\mathrm{~V})$ is $\mathrm{gc}^{*}$-closed in $\mathrm{X}$ for every gc*-closed set $\mathrm{V}$ in $\mathrm{Y}$.

Example: 4.2 Let $\mathrm{X}=\{\mathrm{a}, \mathrm{b}, \mathrm{c}, \mathrm{d}, \mathrm{e}\}$ and $\mathrm{Y}=\{1,2,3,4\}$. Then, clearly $\tau=\{\phi,\{a\},\{d\},\{e\},\{a, d\},\{a, e\},\{d, e\},\{a, d, e\}, X\}$ is a topology on $X$ and $\sigma=\{\phi,\{1\},\{3\},\{4\},\{1,3\},\{1,4\}$, $\{3,4\},\{1,3,4\}, Y\}$ is a topology on $\mathrm{Y}$. Define $\mathrm{f}: \mathrm{X} \rightarrow \mathrm{Y}$ by $f(a)=f(d)=3, f(b)=f(c)=2, f(e)=4$. Then the inverse image of every gc*-closed set in $\mathrm{Y}$ is $\mathrm{gc}^{*}$-closed in $\mathrm{X}$. Hence $\mathrm{f}$ is gc*-irresolute.

Proposition: 4.3 Let X,Y be two topological spaces. Then $\mathrm{f}: \mathrm{X} \rightarrow \mathrm{Y}$ is $\mathrm{gc}^{*}$-irresolute if and only if $\mathrm{f}^{-1}(\mathrm{U})$ is gc*-open in $\mathrm{X}$ for every gc*-open set $\mathrm{U}$ of $\mathrm{Y}$.

Proof: Suppose f: $\mathrm{X} \rightarrow \mathrm{Y}$ is gc*-irresolute. Let $\mathrm{U}$ be an $\mathrm{gc}^{*}$-open set in $\mathrm{Y}$. Then $\mathrm{Y} \backslash \mathrm{U}$ is a $\mathrm{gc}^{*}$-closed set in $\mathrm{Y}$. This implies, $f^{-1}(Y \backslash U)$ is a $g^{*}{ }^{*}$-closed set in $X$. Since $f{ }^{-}$ ${ }^{1}(Y \backslash U)=X \backslash f^{-1}(U)$, we have $X \backslash f^{-1}(U)$ is a gc*-closed set in $X$. This implies, $\mathrm{f}^{-1}(\mathrm{U})$ is a $\mathrm{gc}^{*}$-open set in $\mathrm{X}$. Conversely, assume that $\mathrm{f}^{-1}(\mathrm{U})$ is $\mathrm{gc}^{*}$-open in $\mathrm{X}$ for every $\mathrm{gc}^{*}$-open set $\mathrm{U}$ in $\mathrm{Y}$. Let $\mathrm{V}$ be a gc*-closed set in $\mathrm{Y}$. Then $\mathrm{Y} \backslash \mathrm{V}$ is gc*-open in $\mathrm{Y}$. Therefore, $\mathrm{f}^{-1}(\mathrm{Y} \backslash \mathrm{V})$ is gc*-open in $X$. That is, $X \backslash f^{-1}(V)$ is gc*-open in $X$. This implies, $f^{-1}(V)$ is $\mathrm{gc}^{*}$-closed in $\mathrm{X}$. Therefore, $\mathrm{f}$ is $\mathrm{gc}^{*}$-continuous.

The irresolute and $\mathrm{gc}^{*}$-irresolute functions are independent. For example, let $X=\{1,2,3,4,5\}$ and $\mathrm{Y}=\{\mathrm{a}, \mathrm{b}, \mathrm{c}, \mathrm{d}\}$. Then, clearly $\tau=\{\phi,\{1\},\{4\},\{5\},\{1,4\}$, $\{1,5\},\{4,5\},\{1,4,5\}, X\}$ is a topology on $X$ and $\sigma=\{\phi$, $\{a\},\{c\},\{d\},\{a, c\},\{a, d\},\{c, d\},\{a, c, d\}, Y\}$ is a topology on $Y$. Define $f: X \rightarrow Y$ by $f(1)=f(2)=a, f(3)=f(4)=f(5)=d$. Then $\mathrm{f}$ is irresolute. Consider the gc*-closed set $\{\mathrm{a}, \mathrm{b}\}$ in $\mathrm{Y}$. Then $\mathrm{f}^{-1}(\{\mathrm{a}, \mathrm{b}\})=\{1,2\}$ which is not a gc*-closed set in $\mathrm{X}$. Therefore, $\mathrm{f}$ is not $\mathrm{gc}^{*}$-irresolute. Define $\mathrm{g}: \mathrm{X} \rightarrow \mathrm{Y}$ by $g(1)=g(4)=g(5)=b, g(2)=g(3)=a$. Then $g$ is gc*-irresolute. Consider the semi-open set $\{a\}$ in $Y$. Then $g^{-1}(\{a\})=\{2,3\}$, which is not a semi-open set in $\mathrm{X}$. Therefore, $\mathrm{g}$ is not irresolute.

Proposition: 4.4 Let X,Y be two topological spaces. Then every gc*-irresolute function is rg-continuous.

Proof: Let $\mathrm{f}: \mathrm{X} \rightarrow \mathrm{Y}$ be a gc*-irresolute function. Let $\mathrm{V}$ be a closed set in Y. Then by Proposition 4.3 [6], $\mathrm{V}$ is

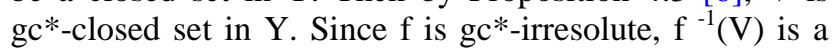
gc*-closed set in X. Therefore, by Proposition 4.7 [6], $\mathrm{f}^{-1}(\mathrm{~V})$ is a rg-closed set in $\mathrm{X}$. Hence $\mathrm{f}$ is rg-continuous.

Proposition: 4.5 Let X,Y be two topological spaces. Then every gc*-irresolute function is gpr-continuous.

Proof: Let $\mathrm{f}: \mathrm{X} \rightarrow \mathrm{Y}$ be gc*-irresolute and $\mathrm{V}$ be a closed set in $\mathrm{Y}$. Then by Proposition 4.3 [6], $\mathrm{V}$ is gc*-closed in $\mathrm{Y}$. Since $\mathrm{f}$ is gc*-irresolute, we have $\mathrm{f}^{-1}(\mathrm{~V})$ is a gc*-closed set in $\mathrm{X}$. Therefore, by Proposition $4.9[6], \mathrm{f}^{-1}(\mathrm{~V})$ is a gpr-closed set in $\mathrm{X}$. Hence $\mathrm{f}$ is gpr-continuous.

The converse of Proposition 4.4 and Proposition 4.5 need not be true as seen from the following example.

Example: 4.6 Let $X=\{a, b, c, d, e\}$ with topology $\tau=\{\phi,\{a\}$, $\{d\},\{e\},\{a, d\},\{a, e\},\{d, e\},\{a, d, e\}, X\}$ and $Y=\{1,2,3,4,5\}$ with topology $\sigma=\{\phi,\{1,2\},\{3,4\},\{1,2,3,4\}, Y\}$. Define $f: X \rightarrow Y$ by $f(a)=2, f(b)=1, f(c)=5, f(d)=3, f(e)=4$. Then $\mathrm{f}$ is rg-coninuous and gpr-continuous. Consider the gc*-closed set $\{1,3\}$ in $Y$. Then $\mathrm{f}^{-1}(\{1,3\})=\{b, d\}$, which is not a gc*-closed set in $\mathrm{X}$. Therefore, $\mathrm{f}$ is not gc*-irresolute.

The gc*-irresolute and w-continuous functions are independent. For example,

1. let $X=\{1,2,3,4,5\}$ and $Y=\{a, b, c, d\}$. Then, clearly $\tau=\{\phi,\{1,2\},\{3,4\},\{1,2,3,4\}, X\}$ is a topology on $X$ and $\sigma=\{\phi,\{a\},\{c\},\{d\},\{a, c\},\{a, d\},\{c, d\},\{a, c, d\}, Y\}$ is a topology on $\mathrm{Y}$. Define $\mathrm{f}: \mathrm{X} \rightarrow \mathrm{Y}$ by $\mathrm{f}(1)=\mathrm{f}(4)=\mathrm{a}$, $f(2)=f(3)=b, f(5)=c$. Then $f$ is $g c^{*}$-irresolute. Consider the closed set $\{\mathrm{a}, \mathrm{b}, \mathrm{d}\}$ in $\mathrm{Y}$. Now, $\mathrm{f}^{-1}(\{\mathrm{a}, \mathrm{b}, \mathrm{d}\})$ $=\{1,2,3,4\}$, which is not a $\mathrm{w}$-closed set in $\mathrm{X}$. Therefore, $\mathrm{f}$ is not a w-continuous function.

2. let $X=\{1,2,3\}$ and $Y=\{a, b, c\}$. Then, clearly $\tau=\{\phi$, $\{2\},\{3\},\{2,3\}, X\}$ is a topology on $X$ and $\sigma=\{\phi$, $\{a\},\{a, b\},\{a, c\}, Y\}$ is a topology on Y. Define $f: X \rightarrow Y$ by $f(1)=f(3)=b, f(2)=a$. Then $f$ is w-continuous. Consider the gc*-closed set $\{a\}$ in $Y$. Then $\mathrm{f}^{-1}(\{\mathrm{a}\})=\{2\}$ is not a gc*-closed set in $\mathrm{X}$. Therefore $\mathrm{f}$ is not a $\mathrm{gc}^{*}$-irresolute function.

Proposition: 4.7 Let X,Y be two topological spaces. Then every gc*-irresolute function is gc*-continuous.

Proof: Let $\mathrm{f}: \mathrm{X} \rightarrow$ Y be a gc*-irresolute function and $\mathrm{V}$ be a closed set in $\mathrm{Y}$. Then by Proposition 4.3 [6], $\mathrm{V}$ is a $\mathrm{gc}^{*}$-closed set in $\mathrm{Y}$. Since $\mathrm{f}$ is $\mathrm{gc}^{*}$-irresolute, we have $\mathrm{f}^{-1}(\mathrm{~V})$ is a $\mathrm{gc}^{*}$-closed set in $\mathrm{X}$. Therefore, $\mathrm{f}$ is gc*-continuous.

The converse of the Proposition 4.7 need not be true as seen from the following example.

Example: 4.8 Let $X=\{1,2,3\}$ and $Y=\{a, b, c\}$. Then, clearly $\tau=\{\phi,\{2\},\{3\},\{2,3\}, X\}$ is a topology on $X$ and $\sigma=\{\phi,\{\mathrm{a}\}, \mathrm{Y}\}$ is a topology on Y. Define $\mathrm{f}: \mathrm{X} \rightarrow \mathrm{Y}$ by $\mathrm{f}(1)=\mathrm{a}, \mathrm{f}(2)=\mathrm{c}, \mathrm{f}(3)=\mathrm{b}$. Then $\mathrm{f}$ is $\mathrm{gc}^{*}$-continuous. Consider the $\mathrm{gc}^{*}$-closed set $\{b\}$ in Y. Then $\mathrm{f}^{-1}(\{b\})=\{3\}$, which is not a gc*-closed set in $X$. Therefore, $f$ is not a gc*-irresolute function.

Proposition: 4.9 Let $\mathrm{X}, \mathrm{Y}$ and $\mathrm{Z}$ be topological spaces. If $\mathrm{f}: \mathrm{X} \rightarrow \mathrm{Y}$ and $\mathrm{g}: \mathrm{Y} \rightarrow \mathrm{Z}$ are gc*-irresolute functions, then gof : $\mathrm{X} \rightarrow \mathrm{Z}$ is gc*-irresolute.

Proof: Let V be a $\mathrm{gc}^{*}$-closed set in $\mathrm{Z}$. Then $\mathrm{g}^{-1}(\mathrm{~V})$ is gc*-closed. This implies, $\mathrm{f}^{-1}\left(\mathrm{~g}^{-1}(\mathrm{~V})\right)$ is $\mathrm{gc}^{*}$-closed. But $\mathrm{f}^{-1}\left(\mathrm{~g}^{-1}(\mathrm{~V})\right)=\left(\mathrm{g} \circ \mathrm{f}^{-1}(\mathrm{~V})\right.$. Therefore $(\mathrm{g} \circ \mathrm{f})^{-1}(\mathrm{~V})$ is gc*-closed in $\mathrm{X}$. Hence, gof is $\mathrm{gc}^{*}$-irresolute.

Proposition: 4.10 Let $\mathrm{X}, \mathrm{Y}$ and $\mathrm{Z}$ be topological spaces. If $\mathrm{f}: \mathrm{X} \rightarrow \mathrm{Y}$ and $\mathrm{g}: \mathrm{Y} \rightarrow \mathrm{Z}$ are gc*-irresolute functions, then gof: $X \rightarrow Z$ is gc*-continuous.

Proof: Let $\mathrm{f}: \mathrm{X} \rightarrow \mathrm{Y}$ and $\mathrm{g}: \mathrm{Y} \rightarrow \mathrm{Z}$ be two gc*-irresolute functions. Let $\mathrm{V}$ be a closed set in $\mathrm{Z}$. By Proposition 4.3 [6], $\mathrm{V}$ is a $\mathrm{gc}^{*}$-closed set in $\mathrm{Z}$. Then $\mathrm{g}^{-1}(\mathrm{~V})$ is

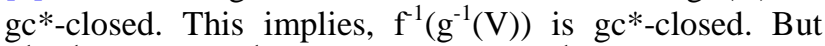
$\mathrm{f}^{-1}\left(\mathrm{~g}^{-1}(\mathrm{~V})\right)=\left(\mathrm{g} \circ \mathrm{f}^{-1}(\mathrm{~V})\right.$. Therefore $(\mathrm{g} \circ \mathrm{f})^{-1}(\mathrm{~V})$ is gc*-closed in $\mathrm{X}$. Hence gof $: \mathrm{X} \rightarrow \mathrm{Z}$ is gc*-continuous.

Proposition: 4.11 Let $X, Y$ and $Z$ be topological spaces. If $\mathrm{f}: \mathrm{X} \rightarrow \mathrm{Y}$ is gc*-irresolute and $\mathrm{g}: \mathrm{Y} \rightarrow \mathrm{Z}$ is continuous, then gof: $X \rightarrow Z$ is gc*-continuous.

Proof: Let $\mathrm{V}$ be a closed set in $\mathrm{Z}$. Since $\mathrm{g}$ is continuous, we have $\mathrm{g}^{-1}(\mathrm{~V})$ is closed in Y. By Proposition 4.3 [6], $\mathrm{g}^{-1}(\mathrm{~V})$ is a $\mathrm{gc}^{*}$-closed set in $\mathrm{Y}$. Since $\mathrm{f}$ is $\mathrm{gc}^{*}$-irresolute, we have $\mathrm{f}^{-1}\left(\mathrm{~g}^{-1}(\mathrm{~V})\right)$ is $\mathrm{gc}^{*}$-closed in $\mathrm{X}$. But $\mathrm{f}^{-1}\left(\mathrm{~g}^{-1}(\mathrm{~V})\right)=\left(\mathrm{g} \circ \mathrm{f}^{-1}(\mathrm{~V})\right.$. Therefore, $\left(\mathrm{g} \circ \mathrm{f}^{-1}(\mathrm{~V})\right.$ is gc*-closed in X. Hence, gof is $\mathrm{gc}^{*}$-continuous. 
Proposition: 4.12 Let $\mathrm{X}, \mathrm{Y}$ and $\mathrm{Z}$ be topological spaces. If $\mathrm{f}: \mathrm{X} \rightarrow \mathrm{Y}$ is $\mathrm{gc}^{*}$-irresolute and $\mathrm{g}: \mathrm{Y} \rightarrow \mathrm{Z}$ is gc*-continuous, then gof : $\mathrm{X} \rightarrow \mathrm{Z}$ is gc*-continuous.

Proof: Let $V$ be a closed set in $Z$. Since $g$ is

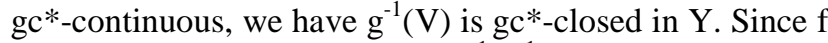
is gc*-irresolute, we have $\mathrm{f}^{-1}\left(\mathrm{~g}^{-1}(\mathrm{~V})\right)$ is $\mathrm{gc}^{*}$-closed in $X$. But $f^{-1}\left(g^{-1}(V)\right)=(g \circ f)^{-1}(V)$. Therefore, $(g \circ f)^{-1}(V)$ is $\mathrm{gc}^{*}$-closed in $\mathrm{X}$. Hence, gof is gc*-continuous.

\section{Conclusion}

In this paper we have introduced gc*-continuous and $\mathrm{gc}^{*}$-irresolute functions in topological spaces and studied some of their basic properties. Also we have studied the relationship between $\mathrm{gc}^{*}$-continuous functions and some of the functions already exist.

\section{References}

[1] N.Levine, Semi-open sets and semi-continuity in topological space, Amer. Math. Monthly., 70 (1963), 39-41.

[2] A.S. Mashhour, M.E. Monsef and S.N. El-Deep, On precontinuous mapping and weak precontinuous mapping, Proc. Math. Phy. Soc. Egypt, 53(1982), 47-53.

[3] M. Stone, Application of the theory of Boolean rings to general topology, Trans. Amer. Math. Soc., 41(1937), 374-481.

[4] A.I. EL-Maghrabi and A.M. Zahran, Regular generalized- $\gamma$-closed sets in topological spaces, Int. Journal of mathematics and computing applications, vol. 3, Nos. 1-2, Jan-Dec 2011, 1-15.

[5] D. Andrijevic, On b-open sets, Mat. Vesnik, 48(1996), 59-64.

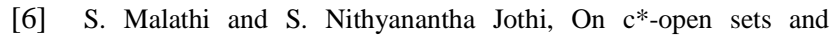

generalized $\mathrm{c}^{*}$-closed sets in topological spaces, Acta ciencia indica, Vol. XLIIIM, No. 2, 125 (2017), 125-133.

[7] N. Levine, Generalized closed sets in topology, Rend. Circ. Math. Palermo, 19(2) (1970), 89-96.

[8] N. Palaniappan, K.C. Rao, Regular generalized closed sets, kyungpook Math. J., 33(1993), 211-219.

[9] Y. Gnanambal, On generalized pre regular closed sets in topological spaces, Indian J.Pure Appl. Math., 28(1997), 351-360.

[10] K. Mariappa, S. Sekar, On regular generalized b-closed set, Int. Journal of Math. Analysis, vol.7, 2013, No.13, 613-624.

[11] A. Vadivel and K.Vairamanickam, rg $\alpha$-closed sets and rg $\alpha$-open sets in topological spaces, Int. J. Math. Analysis, 3 (37) (2009), 1803-1819.

[12] D. Iyappan and N. Nagaveni, On semi generalized b-closed set, Nat. Sem. on Mat. and comp.sci, Jan(2010), Proc.6.

[13] P. Sundaram, M. Sheik John, On w-closed sets in topology, Acta ciencia indica, 4(2000), 389-392.

[14] M.K.R.S. Veera kumar, On $\hat{g}$-closed sets in topological spaces, Bull. Allah. Math. Soc, 18(2003), 99-112.

[15] S. Malathi and S. Nithyanantha Jothi, On generalized c*-open sets and generalized $\mathrm{C}^{*}$-open maps in topological spaces, Int. J. Mathematics And its Applications, Vol. 5, issue 4-B (2017), 121-127.

[16] R.C. Jain, The role of regularly open sets in general topological spaces, Ph.D. thesis, Meerut University, Institute of advanced studies, Meerut-India, (1980).

[17] T. M. Nour, (1995), Totally semi-continuous function, Indian J. Pure Appl. Math., 7, 26, 675-678.

[18] S.S. Benchalli and U. I Neeli, Semi-totally Continuous function in topological spaces, Inter. Math. Forum, 6 (2011), 10, 479-492.

[19] Hula M salih, semi-totally semi-continuous functions in topological spaces, AL-Mustansiriya university collage of Educaion, Dept. of Mathematics.

[20] P. Sundaram and M. Sheik John, Weakly closed sets and weak continuous functions in topological spaces, Proc. 82nd Indian Sci.cong., 49 (1995), 50-58.

[21] S.G. Crossley and S.K. Hildebrand, Semi-topological properties, Fund. Math., 74 (1972), 233-254. 